\title{
Hacia una ontología de la Agri-Cultura en perspectiva del pensamiento ambiental*
}

\author{
Omar Felipe Giraldo
}

Universidad Autónoma Chapingo, México. Email: omarfgiraldo@hotmail.com

Resumen: Desde el enfoque del pensamiento ambiental estético-complejo, el artículo presenta un esbozo de lo que podría llamarse una ontología de la agricultura. Su objetivo es aportar con algunas reflexiones para la construcción de una epistemología de los estudios agroecológicos.

Palabras clave: filosofía ambiental, ética ambiental, epistemología de la agroecología, teoría de los estudios rurales.

\section{Towards an ontology of Agri-Culture on the perspective of environmental thinking}

\begin{abstract}
From the perspective of the esthetic-complex environmental thinking, the article presents an outline of what might be called an ontology of agriculture. Its purpose is to provide analysis for the construction of an epistemology of agroecological studies.

Key words: environmental philosophy, environmental ethics, epistemology of agroecology, theory of rural studies.
\end{abstract}

\section{Rumo a uma ontologia da Agri-Cultura em perspectiva do pensamento ambiental}

Resumo: Do ponto de vista do pensamento ambiental estético-complexo, o artigo apresenta um esboço do que poderia ser chamado de uma ontologia da agricultura. O objectivo é proporcionar com algumas idéias para a construção de uma epistemologia dos estudos agroecológicos.

Palavras-chave: filosofia ambiental, ética ambiental, epistemologia da agroecologia, teoria de estudos rurais.

$* * *$

\section{Introducción}

Un hombre en corbata sentado sobre un taburete, observa desde la altura un barbecho delineado ortogonalmente que se antoja desértico. El terreno del que está distanciado y que aprehende analíticamente, ha quedado devastado por la presión de los discos de arado y por los profusos quí- 
micos que su compañía ha vertido sobre la piel de la tierra. El campo bajo sus lujosos zapatos es ahora un continuo desolado, empobrecido y desnudo. Luce un espacio opaco y silenciado, aniquilado selectivamente por un monocultivo uniforme que ha sido instalado a contranatura, para responder a la insaciabilidad de un mercado cuyos principios no entienden los principios que hacen posible la vida.

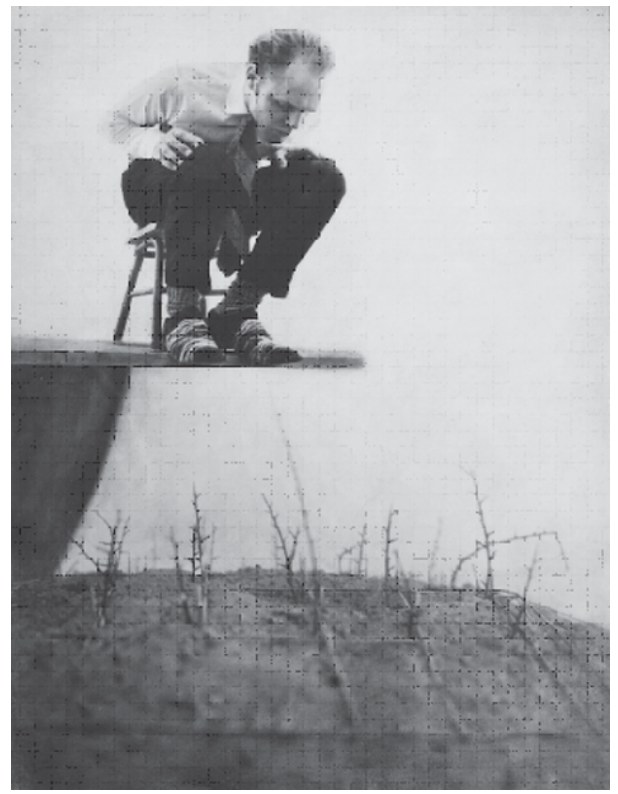

Sin embargo, la tragedia que nos narra la obra de Robert y Shana Parke Harison, no solo acaece para un suelo explotado y destruido; también el oficinista, quien ha querido interponer violentamente el modelo de la fábrica como modelo a la naturaleza (Shiva, 2007), ha quedado aislado y solitario. Totalmente desarraigado y despojado de significaciones: constituido a sí mismo bajo el racional industrial de la línea de montaje.

Podríamos comenzar así sospechando cómo la "revolución verde", en su prisa por dirigir, controlar y ordenar geométricamente los espacios para la producción de alimentos, también ha degenerado en formas del ser humano, congruentes con esas mismas prácticas que divorcian, desplazan y disciplinan la biodiversidad de la Tierra. Es decir, podría pensarse que no solamente estamos habitando un planeta cada vez más pobre, homogéneo, desacralizado y desértico, sino que el antiguo y originario agricultor -en una acepción real y metafórica de la condición humana- también se ha transformado en algo parecido a lo que realiza durante la actividad del monocultivo: una persona cada vez más uniformada, aislada, solitaria, desconfiada y competitiva. 
"Somos lo que hacemos", es el aforismo que subyace tras la anterior afirmación, el cual encuentra respaldo biológico en la teoría de la autopoiesis $^{1}$ de Humberto Maturana y Francisco Varela (2003). Con estos neurobiólogos, se quiere hacer alusión al hecho de que nuestro ser es una continua creación humana. Es decir, que los humanos -y los demás seres vivos-, nos hacemos a través de la experiencia cotidiana. Ser de una forma específica y el hacer habitual, aseguran Maturana y Varela, van siempre de la mano, deben entenderse conjuntamente. Ello significa que el monocultivo y su lógica, no son separables de la comprensión del ser mismo de quien realiza esa actividad, pues ambos están en una coo-determinación mutua; están emergiendo en una permanente relación recíproca. De ahí que si bien el hombre del performance de Robert y Shana ParkeHarison -un hombre abstracto que encarna la crisis de una cultura-, es el creador de un sistema de cultivos industriales, simultánea y continuamente, el propio sistema también es creador de ese mismo hombre.

En este ensayo deseo mostrar que el hacer de la agricultura tradicional -el cual aún subsiste en más de la mitad de la tierra cultivada en el mundo-, ha determinado diversas maneras de ser de sus agricultores, quienes se han creado a sí mismos por obra de la actividad agrícola. La agricultura no es por tanto, un tema que deba reducirse a la productividad, sino un asunto profundamente ontológico, que ha conformado por milenios las formas del ser, el habitar y el permanecer de la humanidad entera, y que en mucho menos de una centuria ha sido irrumpida por un modelo fabril homogeneizante, cuyo racional percibe a la tierra como un depósito de recursos muertos que podrán ser extraídos para siempre.

Quizá un corto acercamiento a la ontología de la agricultura, pueda servir de ayuda para comprender de manera mucho más profunda e integral, la importancia -no solo productiva-, de los estudios agroecológicos.

\section{La Agri-Cultura}

Para entender la ontología de la agricultura, el ser mismo de la labor que hace seres humanos, es necesario comprender el sentido primigenio y etimológico de la palabra. El vocablo agricultura está conformado por dos derivaciones latinas: Agri- de agri, que expresa "arte de cultivar el campo", y -Cultura, del verbo Colere, cuya raíz originaria quiere decir "cultivar" y "habitar", de manera que el significado profundo de la palabra Agri-Cultura es "el arte de cultivar y habitar la tierra".

Cuando se hace referencia al habitar, como expresión constitutiva de la Agri-Cultura, se le está entendiendo con Heidegger (1994a; 1994b) como el rasgo fundamental del estar del ser humano. Habitar es la posibilidad de morar junto a los demás, con lo Otro, con todo aquello que no soy yo mismo. Habitar y Cultivar en su sentido más amplio, implica cuidar la vida, rodearla de abrigo, envolverla en un buen trato. Tratar bien, es esta- 
blecer las condiciones adecuadas para residir junto a la totalidad de lo existente. Es: "preservar el mundo y conservarlo para lo advenidero" (Janke, 1988:53).

Tratar bien, es cultivar la red de interconexiones que hacen posible la vida. Dejar ser a la tierra como tierra, el agua como agua, y el bosque como bosque (Heidegger, 1994b). Separarse para que lo cuidado vuelva a sí mismo; retirarse por un tiempo para que lo amparado descanse en su más pura esencia. Abrigar, cuidar, tratar bien, enuncia estar en estados de quietud y serenidad, es a veces "no hacer", dejar las cosas en su más íntima libertad. No se trata de no hacerle nada a lo cuidado, sino en no pretender tirar de la semilla para que al caprichoso antojo el tallo brote de la tierra. Cuidar consiste en prestar protección, amparar, albergar, para que la semilla en toda su libertad crezca como ella realmente es.

Habitar como agricultores es residir con lo demás. Un acto poético del cuidado de todo aquello junto a lo cual se mora. Agri-Cultura en su prefijo Agri- significa arte, un arte de cultivar y habitar la tierra, un acto poético de albergar el nacimiento, crecimiento y reproducción de los ciclos naturales de la vida, pero también, de acuerdo a su sufijo -Cultura, es creación -poiesis- de las condiciones favorables para la permanencia de nuestra especie en la Tierra. Somos animales que sobrevivimos gracias a la cultura (Geertz, 1991), razón por la cual Agri-Cultura podría igualmente entenderse como el arte creador de nuestro ser sedentario que nos ha permitido, durante los últimos diez mil años, el prodigio natural del permanecer.

Es necesario advertir que el habitar humano no consiste en vivir sin intervenir los ecosistemas. Antes bien, para sobrevivir, hombres y mujeres, hemos tenido que transformar el medio, porque la cultura, de la que somos producto, no puede prescindir de las modificaciones de la naturaleza (Ángel, 1996). Somos emergencia de esa intervención, la cual desde el periodo neolítico, ha sido definitivamente Agri-Cultural. Con ello quiero decir, que pese a los impresionantes desarrollos científico-técnicos de la vida urbana contemporánea, la Agri-Cultura sigue siendo la base biológica que nos sigue permitiendo el permanecer. Dicho de otra manera: a partir de la revolución de la Agri-Cultura se crean las formas permanentes de subsistencia para la especie humana (Ángel, 1995), en el sentido de que tal vez todo haya cambiado en el transcurrir de los últimos diez milenios, salvo que la vida humana sigue dependiendo del arte de la Agri-Cultura.

Esta gran revolución implicó una transformación radical de los ecosistemas (Ángel, 1995), pero también con este nuevo hacer, el humano se hizo ontológicamente distinto de aquel nómada cazador que le había precedido. Una comunidad pre-agrícola no podía sentir de la misma manera, ni con la misma intensidad, el arraigo y la pertenencia a la tierra. Por eso, la cultura en transformación tuvo que remplazar los símbolos de la sociedad cazadora y recolectora, por otros símbolos relacionados con la sexualidad, la fecundidad, la sacralidad de la mujer y la tierra (Eliade, 1981). 
Las evidencias arqueológicas de seis milenios de antigüedad, muestran cómo la Diosa-Madre -el más importante de los nuevos símbolos que había traído la Agri-Cultura- aparece acompañada de árboles, cabras, serpientes, pájaros, huevos y plantas, lo que muestra la rendición de culto a la deidad femenina y la fertilidad, así como la unión entre seres humanos y naturaleza (Lerner, 1990). Asimismo, el símbolo de la madre tierra, que emerge con la Agri-Cultura, expresa claramente el sentimiento de saberse hijos de la tierra, y cómo la experiencia religiosa se vuelve mucho más concreta: se difumina íntimamente con la semilla, el suelo, y la lluvia. Se mezcla más profundamente con la vida (Eliade, 1981).

La Agri-Cultura hace una trascendental ruptura del paso de las sociedades nómadas a sedentarias, cambio que implica que las personas se sientan "gente del lugar". El desplazamiento da paso a un habitar enraizado a un lugar apropiado, en el cual desarrollar la existencia humana. El habitáculo aldeano se vuelve el espacio circunvecino del trigo, el maíz, el arroz, y los animales domésticos, y con ellos los lugares se convierten en plétoras de símbolos, rituales y prácticas. Con la Agri-Cultura la naturaleza se arraiga localmente al lenguaje, a las representaciones culturales y a las aprehensiones cognitivas. Volverse sedentario quiere decir que el ser ha encontrado un lugar permanente para morar -el lugar del ser-, y que en consecuencia, la historia se hará específica al lugar.

Gracias a la Agri-Cultura se han domesticado los lugares. Domesticar en el entendido de "crear vínculos" (Saint- Exupèry, 1953), lo que representa que aquellos lugares se han vuelto espacios para el habitar, lugares domesticados que ya no serán iguales a los demás. Serán de ahora en adelante sitios únicos: hogares en dónde resolver la existencia humana.

Con la Agri-Cultura esos lugares serán transformados, intervenidos, inscritos: se han inventado hábitats distintos a los naturales; ecosistemas transformados que han hecho al habitante (Pardo, 1991). De manera que tal modificación no corresponde a un acto unidireccional por el cual únicamente se ejerzan afectaciones sobre el mundo natural. El ecosistema transformado también afecta el ser de ese ser humano. Sembrar, por así decirlo, es "sembrarse a sí mismo", pues se es como se es en cuanto incidencia de dicha modificación. Con la intervención de la Agri-Cultura no solo se han construido otras formas de naturaleza, sino que ha acontecido para el naciente agricultor una honda transformación ontológica. Su ser se ha determinado de acuerdo con el ser de ese medio modificado.

\section{Conocer afectivamente el lenguaje de la naturaleza}

En la obra, En el Huerto, de Vincent Van Gogh, puede apreciarse al campesino en absoluta sumisión y respeto, prestando atención a las raíces del árbol que crece en el terruño donde ha establecido su refugio. Con su pala está prestándole abrigo. Está conociéndolo, reconociéndolo. Pero no de manera racional y lógica. Es más bien conocer el mundo que produce 
afecciones, sentimientos y sensaciones. Un conocer ritual, simbólico y mítico. Una celebración emocional de poder residir junto al árbol que en algún tiempo procurará su fruto.

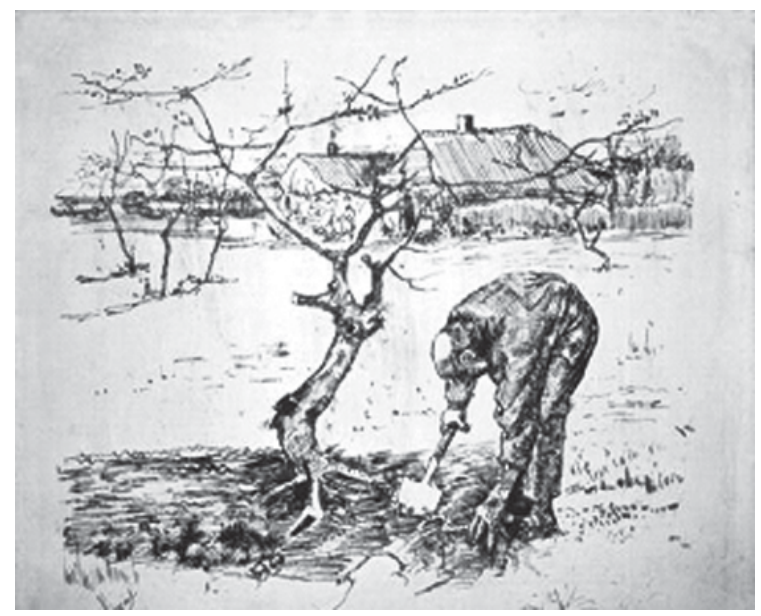

Vicent Van Gogh. En El Huerto, 1883.

La litografía de Van Gogh sirve para entender estéticamente cómo además de la continuidad entre el ser y el hacer, toda modificación del ecosistema implica la interacción con los elementos de la naturaleza, proceso durante el cual se deriva conocimiento de ese mundo vivido. En términos de Maturana y Varela (2003: 13) “todo hacer es conocer”, pues no es posible conocer sino aquello que se hace, y en tal orden de ideas, el saber de los campesinos, necesita de esa experiencia cotidiana arraigada a un lugar domesticado.

Conocer como campesinos no equivale al raciocinio preciso, exacto y expresable matemáticamente de la ciencia moderna. Es en cambio, comunicación afectiva que intenta comprender el lenguaje de la naturaleza. Una lengua “deslenguada”, asegura José Luis Pardo (1991: 112): “un lenguaje que no es lo que los hombres dicen del mundo... sino que es el lenguaje del mundo”.

Conocer afectivamente, es comprender esa forma de hablar, es auscultar la relacionalidad entre seres vivos; es escuchar la complementariedad, la reciprocidad, la asociación solidaria y ayuda mutua, y todas esas maneras por las cuales la naturaleza se expresa. Conocer es descubrir cómo la semilla retorna en cada ciclo; comprender cómo la fertilidad regresa luego del descanso y la quietud del terreno; cómo el periodo de lluvias o las estaciones vuelven periódicamente. Conocer afectivamente quiere decir 
también obedecer: entender cuándo no debe hacerse todo aquello que puede hacerse. Entender que no se rompen los equilibrios bióticos o se transgreden los nichos naturales de plantas y animales, y sus relaciones simbióticas, sin afectar al mismo tiempo nuestro ser y la posibilidad misma de seguir permaneciendo.

El conocer afectivo es erudición emocional anclada al territorio en donde se desenvuelve la existencia cotidiana. Es comunicación efectiva, conversación, diálogo. Así como el campesino de Van Gogh le habla al árbol con el que ha creado vínculos en su huerto, igualmente el árbol le contesta en su propia lengua. Una charla directa que acontece durante el arte del cultivo y el trabajo. Un diálogo íntimo entre el agricultor y las fuerzas vitales, una comunicación permanente viabilizada e intermediada por las labores de labranza, siembra, aporque y cosecha.

El campesino conoce porque la naturaleza le habla. Y es por eso que existe el saber del campesino. Al interpretar su lengua, sabe del comportamiento de las lluvias y los cultivos adecuados al lugar donde ha fincado su morada; reconoce las semillas resistentes a las sequías o inundaciones; o la necesaria unión entre el bosque y el campo en el que ha establecido su plantío. El saber localizado supone un profundo conocimiento de las interacciones entre las especies y sus relaciones con el cosmos: es saber que su comportamiento está indisolublemente asociado a los acontecimientos lunares y los ciclos temporales. Escuchar el lenguaje de la naturaleza es atender que su voz -especialmente en áreas equinocciales- es la voz de la diversidad y que una Agri-Cultura no puede ser de otra forma sino diversa.

La milpa mesoamericana es muestra de cómo el campesino ausculta la diversidad de la naturaleza al sembrar el maíz en "barrocos jardines" (Bartra, 2010); porque interpretar la palabra de los bosques es sembrar la tierra en forma de policultivo. La milpa es la expresión de que un buen trato con la tierra generosa debe mantener las relaciones bióticas del ecosistema, los ciclos de nutrientes, y las recirculaciones de agua y energía, que acontecen en el mundo simbiótico de las complementariedades. Captar cómo lo uno no se produce sin lo otro, cómo en la entremezcla solidaria las cosas funcionan juntas: juntas conviven, juntas dialogan y juntas se hacen compañía. Hacer policultivo es advertir la incompletud de cada ser aislado de su nicho asociativo, es cuidar los bucles que hacen que la vida sea vida, al amparo de la reciprocidad mancomunada.

La Agri-Cultura consiste en atender las señales de la naturaleza: saber que puede reducirse el riesgo de enfermedades al conocer los efectos de los doseles sobre algunas hierbas; percatarse de que los cultivos deben rotarse e intercalarse como milpas; reconocer la necesidad de mantener la cobertura vegetal sobre la piel de los suelos, y entreverar plantas con efectos alelopáticos, repelentes o insecticidas (Altieri, 1999). Hacer Agri-Cultura exige un cuidadoso entendimiento de la fertilidad de la tierra, las interrelaciones naturales necesarias para la siembra y cosecha, y de los ciclos de vida de los animales que habitan en el cultivo. La Agri-Cultura no 
es dominación, manipulación, o sojuzgamiento; es, en cambio, diálogo, adecuación y congruencia entre la siembra y cría de animales con el ser de la naturaleza.

Conocer su ser, significa comprender que los sistemas vivos son cíclicos y autopoiéticos, lo cual quiere decir que cada uno de los elementos de la cadena trófica cumple la función de transformar a los otros componentes de la red, en un continuo recircular, de modo que lo que es residuo para una especie constituye alimento para la otra (Capra, 1998). El agricultor que se comunica afectivamente con la tierra, sabe que la naturaleza le permite su permanecer solo si integra su práctica a la cadena trófica del ecosistema, lo cual logra, por ejemplo, al enriquecer el suelo del cultivo con el humus del bosque, o al hacer abono con el estiércol de sus animales domésticos.

El conocer afectivo de la Agri-Cultura ha permitido el permanecer durante centenares de siglos, en la medida en la que se ha hecho un acoplamiento compatible entre las transformaciones culturales hechas al ecosistema y los ciclos ecológicos que rigen la vida. Si no fuera así, no se habrían generado las condiciones de subsistencia de la especie, como lo enseña la historia catastrófica de aquellos pueblos extintos que han creado In-Culturas incongruentes con las condiciones de existencia de su morada.

El conocimiento derivado a partir de las prácticas agrícolas es entonces el saber que ha creado las condiciones biológicas de supervivencia de nuestra especie en el planeta. Si la modificación realizada por la AgriCultura se hubiera sustentado en el principio de la depredación de los suelos y la destrucción de la biodiversidad, no se habría generado el acoplamiento necesario entre nuestro ser y el medio, y en consecuencia, la interacción circular y regeneración natural de los ecosistemas transformados se habría interrumpido, lo que biológicamente habría significado la extinción del animal humano sobre el planeta.

Conocer afectivamente es entender los bucles por los cuales la naturaleza se crea a sí misma, bucles a los cuales la Agri-Cultura armónicamente se integra. Es el arte de saber cómo acoplarse equilibradamente a las constantes auto-formaciones de los ecosistemas.

\section{El culto a la sacralidad de la tierra}

Se ha argumentado hasta ahora que el campesino deriva conocimiento del mundo vivido, pero no hay que olvidar que al mismo tiempo se mantiene en el enigma de todo aquello que no deja conocerse. Subsiste en una permanente tensión entre aquello que puede interpretarse del lenguaje de la tierra y el misterio de aquello que no deja descubrirse. Por eso los campesinos de El Angelus de Millet, rinden culto a ese secreto que a la razón siempre permanece oculto. 


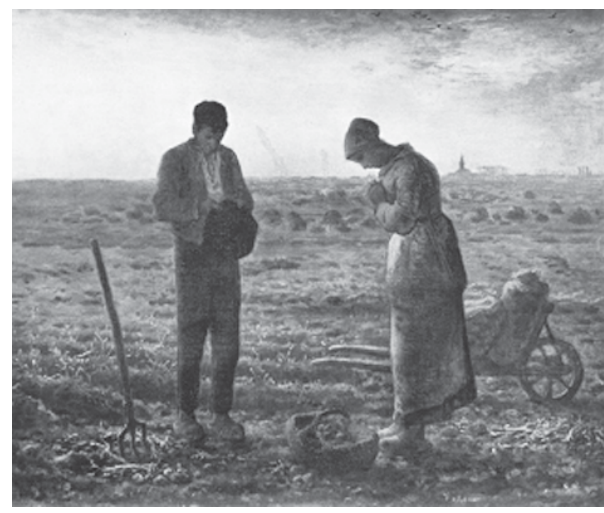

Jean François Millet. El Angelus, 1860

La chacra, la parcela o la milpa para el agricultor no es espacio equiparable al resto de los lugares. Es el "aquí" desde el cual se construye "un mundo". Es territorio en el que se dialoga con el sinfín de fuerzas vitales con las cuales co-existe. Es tierra arada que se ha vuelto cualitativamente diferente a la tierra colindante: un asentamiento consagrado por medio del trabajo. No es espacio homogéneo, desacralizado o profano (Eliade, 1981) como el de la producción fabril de alimentos. Es el lugar delimitado por el afecto construido durante las faenas de labranza. Tierra trascendente. Sitio desde el cual se rinde culto a las interconexiones de la vida.

Los campesinos de Millet ofrendan la cosecha mirando el suelo con veneración y reverencia. No son productores o pequeños empresarios agrícolas. Mucho más que eso. Son Cultores, Agri-Cultores. Cuidadores dedicados al cultivo del campo que ofrece el alimento. Guardianes que albergan la tierra sobreabundante. Su trabajo es culto originario, un ritual en el que se consagra la parcela para convertirla en fuente de fecundidad y de vida. De modo que el Agri-Cultor no solo transforma físicamente los ecosistemas, también, simbólicamente, los convierte en microcosmos, en oikos, en pequeños universos (Eliade, 1981). En los espacios en donde los terrones cavados se relacionan con el sol, las lluvias y la luna.

El rito agrícola para el Agri-Cultor es la fundación de su propio mundo (Eliade, 1981). No "del mundo", sino de "un mundo" intrínsecamente asociado a la interacción vivida desde el punto de referencia que representa su milpa, su chacra o su parcela. El campesino está arraigado a la naturaleza mediante actos prácticos (Escobar, 2000), y a través de los mismos, establece un pequeño universo dotado de diversas significaciones.

Pero fundarse un "mundo" además de un acto cúltico, es práctica poética, como es expresado por Friedrich Hölderlin cuando escribe "lo que permanece, lo fundan los poetas” (Heidegger, 1983). Y si fueran ciertas las 
palabras de Hölderlin ¿no podría pensarse al Agri-Cultor haciendo poesía? ¿O no es acaso poético hincar los surcos de labranza y abrir el suelo para unir el cielo y la tierra, permitiendo que el agua lluvia y el sol penetren la semilla virgen para hacer posible el milagro de la vida? Al hacer AgriCultura el buen Agri-Cultor forja poesía, en cuanto el buen trato con la tierra labrada permite que los demás también habiten; funda lo que permanece porque al cultivar poéticamente custodia y ampara, y al fundar su "propio mundo" -y asumir la responsabilidad de su cuidado- consigue que la tierra provea el alimento que permite a todos la posibilidad de seguir permaneciendo.

Horadar la tierra es poesía, cuando la pica plasma signos en compañía de la cubierta vegetal que protege el lienzo sobre el cual se labra. Y es poético porque permanece, en el sentido de que privilegia lo que adviene, dejando que el habitar también habite (Heidegger, 1994b). La Agri-Cultura es Cultura, porque favorece que la producción de la tierra fecunda perdure más allá del corto plazo, y asegura la provisión de alimentos para la descendencia que aún no habita. Y es por eso que el Agri-Cultor no es un productor, sino Cultor que transforma la tierra poetizando, inscribiendo surcos como pliegues del cutis de la tierra; moldeando arrugas temporales que se pliegan y repliegan (Noguera, 2004).

La parcela es pues tierra sagrada a la que se le rinde culto. Deja conocerse al dejar evidenciar las relaciones cíclicas entre los seres que la componen, al mostrar el constante retorno a la tierra cuando las hojas de las plantas caen al suelo, se convierten en humus y luego la humedad se evapora de sus entrañas. Pero al mismo tiempo que la naturaleza muestra, a la vez, se retira. Deja aprehender sus relaciones simbióticas y al mismo tiempo se oculta a los ojos de quien racionalmente pretende conocerla (Heidegger, 1994c). El Cultor así lo sabe, cuando no la trata como objeto cognoscible sino como madre nutricia. Como el ser vivo que ofrece el conocimiento de todo aquello que sabemos, pero que mantiene el enigma solo accesible a los oídos de la poesía.

Por eso Cultivar es poesía. Un canto expresado en el sinnúmero de coplas bucólicas del campesino que ofrenda la tierra. No es saber explicable y medible, sino música vivida, poesía campirana dedicada por un Cultor siempre abierto al misterio de la vida.

\section{Ontología del Agri-Cultor}

Es necesario aclarar que por Agri-Cultor se está haciendo referencia a esas personas vivas de carne y hueso que labran más de la mitad de la tierra agrícola del mundo, así como también, a los agentes históricos que han creado las condiciones de subsistencia del corto trasegar de la especie humana sobre el planeta. Sin embargo, también se le está tomando en sentido metafórico, para representar por contraste, al ser de esos animales que se han extraviado de la tierra. En cualquiera de los casos, comprender la 
ontología del ser creado a partir de la Agri-Cultura, implica entender la condición afectiva, poética, estética y simbólica (Janke, 1988), que supone el estar arraigado a lugares concretos. Al hecho de pensar, sentir, y actuar desde alguna parte.

La condición afectiva hace alusión al ser que es afectado por su pertenencia a la tierra. A la alteración emocional que invade el cuerpo por el inherente vínculo que une al ser del Agri-Cultor y al lugar en el que cuida su cultivo. Como Heidegger (1994a) explica, no hay un espacio en un lado y una persona en el otro, pues el lugar, en este caso la parcela, no es exterioridad que pueda ponerse frente a un campesino insensible e inerte. Modificar los ecosistemas significa afectar el orden natural originario (Ángel, 1996), pero también, representa ser afectado por la creación de ese ambiente en co-emergencia, de ese ambiente rural, en permanente co-surgimiento por la interacción entre el Agri-Cultor y el medio transformado. La parcela es ambiente en florecimiento, lugar vivido y habitable. Un espacio sentido íntimamente por un jardinero que lo ha preservado y resguardado.

Mediante su trabajo el campesino traza sentimientos, sensaciones, afectos, incorporados en su propio cuerpo. La parcela está escrita en las manos, los brazos, la espalda, las piernas y el sudor de quien la labra (Pardo, 1991). "Crear vínculos” es afecto empático, lo que significa que cualquier perturbación a esa tierra domesticada, es capaz de manifestar perturbaciones que recorren los cuerpos de sus campesinos. Esa parcela es el producto de la modificación hecha al ecosistema, pero también, durante la moldura de sus pliegues, el modo de ser de sus escultores es afectado consistentemente. La milpa, la parcela, la chacra habita en el Agri-Cultor del mismo modo que él habita en ella. Cuerpo y tierra no son más que la misma cosa (Noguera, 2009), lo que es solo una manera de decir, que la modificación del ecosistema se expresa en todos y cada una de las características de un cuerpo habitado que habita la tierra.

Entender la existencia de ese ser que se hace uno con la tierra, es comprender que en realidad nunca está solo, que es un cuerpo habitado en el que se halla la chacra labrada. De manera que es posible conocer el ser del Agri-Cultor al conocer su granja, así como conocer la granja conociendo su ser. La ontología del Agri-Cultor exige estar abierto a una comprensión poética de quien se ha fundido en la tierra sin perderse a sí mismo. Un habitar dialéctico en constante correspondencia, que es justamente la manera por la cual el Agri-Cultor existe.

Por existir hay que entender la noción latina de la palabra: ex-sistire, cuyo significado es volcarse hacia afuera de su propia esencia. Quiere decir "estar abierto" (Eliade, 1981) a un mundo que habla y que da señales. No se vive aisladamente sino siempre se existe con Otros: otros humanos, otros animales, otra agua o montaña. El Agri-Cultor existe cuando su ser se vuelca hacia afuera y habita en comunidades humanas y naturales. Habitar afectivamente -o lo que es lo mismo: existir- está plenamente asociado a vivir abiertamente hacia el mundo, no dejar de tener nada junto, ser como 
se es, de acuerdo a la convivencia con la alteridad de la que se es dependiente y a la que se está interrelacionado.

Comprender la condición poética del Agri-Cultor es entender el repertorio de símbolos, rituales y afectos que lo unen y conectan con la tierra. Aprehenderlo, ante todo, como un tendedor de puentes entre el conjunto de los fenómenos naturales (Estermann, 1998). Por puente hay que concebir el medio por el cual de un lado se puede ir hacia el otro, pues en cuanto puente se pasa igualmente de orilla a orilla; se logra estar en un lugar como en el otro; se va y se viene del mismo modo (Heidegger,1994a). Con las faenas agrícolas el Agri-Cultor no pretende dominar la tierra como lo indica el encargo del Génesis bíblico; muy al contrario, intenta relacionar transformando, extendiendo puentes para juntar la tierra y el cielo, el bosque y el campo, el maíz con el frijol, la semilla y el estiércol. Cultivar tendiendo puentes, es un acto ritual, poético, simbólico y estético, por el cual el AgriCultor al transitar por el puente, paulatinamente, se va convirtiendo en "Cuerpo-tierra” (Noguera, 2004).

El Cuerpo-tierra quiere dar cuenta de que nutrir la tierra durante la Agri-Cultura equivale a nutrirse a sí mismo. Es el juego de intercambios recíprocos de una tierra que, al nutrirse, igualmente nutre. En palabras de Michel Foucault (2006) es “cuidado de sí”, porque el arte de la existencia el $e x$-sistire - se encuentra permeado por la seguridad de que cuidando de lo demás se cuida de uno mismo. Corresponde a la convicción de que al entendernos como seres interrelacionados a la complejidad de hilos de la vida, custodiar a lo Otro, quiere decir “custodiar de sí mismo”.

Pero también decir Cuerpo-tierra es una forma de evocar las maneras por las cuales nos comunicamos con la naturaleza cuando "sentimos el dolor de la sequía, la alegría de la lluvia, la angustia de los peces sin oxígeno, la fealdad de la destrucción" ${ }^{2}$, y en suma, toda esa capacidad que tiene nuestra especie -compartida con los demás homínidos superiores (Varela, 2000) - de ser afectados en nuestro propio cuerpo por la afectación de una Tierra de la que somos integrantes.

La condición estética del Agri-Cultor se entiende cuando concebimos la transformación de los ecosistemas como dibujos sobre los espacios, escrituras sobre la piel de la tierra que conforman hábitats (Pardo, 1991), invenciones geográficas de lugares esbozados por las manos campesinas. Geo-Grafía significa "escritura de la tierra”, por lo que crear Geo-Grafías es cifrar marcas delebles diseñadas durante los quehaceres de la Agri-Cultura. Como tendedor de puentes el Agri-Cultor relaciona, aunque siempre le resulte claro que las relaciones naturales nunca necesiten de su intervención, salvo de las semillas y animales que ha domesticado. Sin embargo desplegando puentes es como hace su tarea. Pinta paisajes porque efectúa la lectura del ecosistema y lo hace con pinceles de azadón al entreverar la yuca, el maíz y el frijol con la ahuyama.

Se trata entonces de un ser que al hacer Agri-Cultura mantiene la 
correspondencia y la solidaridad biótica de la naturaleza. Reordena los espacios modificando, poetizando, arando. Pero no son ambientes hechos a contranatura, sino paisajes ecológicos en los que conserva el nicho de las especies vegetales y animales, es decir, se escribe en la tierra al comprender las funciones que ejerce cada especie dentro del ecosistema (Ángel, 1996). Teñir la tierra pincelando paisajes agrícolas en forma de terrazas andinas, por ejemplo, es reorganizar completamente los espacios atendiendo siempre las señales que indican cómo darle preeminencia a las interrelaciones naturales. Al sembrar policultivos se urden hábitats y se habita estéticamente, y es por eso que sobre la milpa, Armando Bartra (2010) sostiene:

“... los mesoamericanos no sembramos maíz, los mesoamericanos hacemos milpa. Y son cosas distintas porque el maíz es una planta y la milpa un modo de vida. ...Solo y su alma el maíz es monotonía mientras que la milpa es de por sí diversidad. En la milpa el maíz, el frijol, la calabaza, el chile, el chayote, el tomatillo, los quelites, los árboles frutales, el nopal, los magüeyes y las vestezuelas del campo se hacen compañía. A diferencia de los uniformados maizales, las milpas son abigarrados policultivos”.

De modo que los policultivos no son plantas que se cultivan al tiempo, mucho más que eso: son "modos de vida”, maneras de fundar "mundos” sobre la base de la diversidad biológica. No de otra manera podrían entenderse los principios organizativos que rigen a tantas culturas originarias de América, las cuales se sustentan sobre la base del ser del policultivo. En ellas el énfasis no se da sobre el individuo, sino que sus paradigmas comunitarios y sus relaciones socioeconómicas se estructuran sobre la base de la pluralidad, la reciprocidad y la complementariedad (Lenkersdorf, 2005). Porque el hacer y el conocer el mundo vivido tienen total correspondencia con ser de una forma concreta, lo que en términos de una ontología de la Agri-Cultura significa que si la experiencia cotidiana acontece en una milpa, no se puede ser de otra forma que no sea como una milpa.

Y una milpa no es competencia entre plantas o entre insectos que quieren desplazar unos a otros, porque la milpa es expresión del ecosistema puesta en el cultivo. Las demás plantas no son rivales que deben destruirse; son colaboradoras, socias, compañeras con las cuales pueden intercambiarse nutrientes, o dialogar para aprovechar mejor la luz y el agua del espacio ocupado (Altieri, 1999). Por supuesto, no se trata de procesos sin conflictos, sino de reacomodaciones y diálogos entre especies; de interacción genética continuada para llegar a arreglos de hibridación y acomodamiento (Shiva, 2007). El derecho consuetudinario indígena lo entiende al basar la solución de sus conflictos mediante el diálogo y el consenso -como en el policultivo-, pues a diferencia del sistema positivo occidental, no se busca la exclusión del agraviante - ni el desplazamiento de malezas- sino que pretende la manutención del equilibrio comunitario mediante procesos argumentativos hasta encontrar un arreglo entre las partes y restablecer la convivencia comunitaria (Collier, 1995). 
Dar prerrogativa al nicho en el cultivo a través de la complementación de especies asociadas, significa escuchar que la naturaleza habla en palabras de la articulación y el equilibrio en lugar de la lucha y la aniquilación. De ahí que el conocer y el hacer de la Agri-Cultura es inmanente a las estrategias de intercambios mutuos, al trabajo colectivo, la reciprocidad económica campesina, y a la vida comunitaria de los pueblos indígenas y afrodescendientes, porque el cultivo no es solo fuente de elementos físicos para la subsistencia, sino el origen de identidades, significados culturales y existenciales de sus Agri-Cultores.

Por eso, más allá de los términos utilitarios en los que la Agri-Cultura es frecuentemente analizada, es necesario entenderla como una forma de habitar y de estar en el mundo. Una manera de existir en interrelación con la naturaleza que incluye consideraciones afectivas, simbólicas, estéticas y poéticas. Una actividad por la cual se construyen personas y culturas que permanecen y que permite que los demás continúen con ellas. Ante todo, la Agri-Culura es un arte por el que se hacen, se forman, se constituyen y son posibles los seres humanos.

\section{La fábrica como espejo de la naturaleza}

Para empezar hay que ubicar a cada cosa en su lugar. La agricultura ecológica no es agricultura alternativa, ni orgánica, ni cualquier otro tipo de apellido subalterizado al modelo de "revolución verde". Tampoco es posibilidad de producción subordinada a un supuesto sistema industrial dominante, ni menos opción de desarrollo sostenible o sustentable, ni de ningún otro apellido del discurso del desarrollo. La agricultura ecológica en todo su sentido es "La Agri-Cultura". El arte de cuidar y habitar la tierra que, incluso en suelos con poca fertilidad o en áreas secas o inundables, durante milenios, ha creado las condiciones adecuadas para el permanecer.

Lo otro: el monocultivo con semillas genéticamente modificadas, y dependiente de fertilizantes químicos, de herbicidas y plaguicidas tóxicos, no puede llamársele nunca "agricultura". Calificar de tal manera a la vulgar producción mecanizada, fabril, lineal y destructora de la naturaleza no es solo un irrespeto frente al arte poético de la real Agri-Cultura, sino que representa un eufemismo que sepulta su real significado. Esta designación en realidad es un nombre falso que oculta, esconde y disfraza su sentido. Cubre con tapujos a una actividad cuyo raciocinio de dominación impide la reproducción de la vida y la viabilidad de la existencia. Según se ha insistido, el ser humano perdura y persiste gracias a la cultura, por lo que llamar "agricultura" a una obra predatoria que niega el cuidado y buen trato necesario para vivir junto a lo Otro, es contradicción inherente, contrasentido, traición a la tierra.

La "revolución verde” es más bien In-Cultura: negación de la cultura. Una de las más claras expresiones del olvido del lenguaje de la natura- 
leza, idioma en el cual pareciera que fuéramos ya incapaces de comunicarnos (Pardo, 1991). La biotecnología y la apropiación industrial de la vida lo han vuelto mudo; le han cortado su lengua al mismo tiempo que sus verdugos degenerado en autistas. Se han amputado los oídos y las enunciaciones proferidas por la pródiga tierra devenido ininteligibles. Los ciclos, relaciones y complementariedades se remplazan por procesos lineales y ensamblajes mecánicos. La naturaleza intervenida ya no es naturaleza autónoma que se hace constantemente a sí misma (Maturana y Varela, 2003), sino que el ciclo se interrumpe al imponer la visión de la fábrica como modelo a la naturaleza (Shiva, 2007). Los acoplamientos entre cultura y ecosistema logrados durante siglos se han roto, y el antiguo arte del cultivo de la tierra se pervierte para dar lugar a infinitas cadenas de desperdicios y contaminantes que proceden del racional de producción originado de la industria.

Los paisajes agrarios se han vuelto paisajes del desarrollo. Ya no biomas en interacción con la diversidad cultural, sino insensibles haciendas agroindustriales mecanizadas para el aseguramiento de divisas de acuerdo con los mandatos del capital. Son ahora espacios homogéneos, señalados y delimitados, en los cuales se han remplazado los enmarañados ecosistemas biológicos por figuras cuadrangulares de la geometría euclidiana. Lo que es caos para la In-Cultura dominante se escinde en orden matematizado. En claras porciones de tierra exacta, precisa y controlable al servicio de los afanes de dominio y explotación de la civilización capitalista. Se han trasladado los registros estéticos de la arquitectura urbana a la ruralidad modernizada (Noguera, 2004), hecho con lo cual el campo -sobre todo en algunas Geo-Grafías- ya no es más propicio que las ciudades para rememorar el antiguo lenguaje olvidado.

Esas inscripciones sobre la tierra no simbolizan sacralidad y culto como en la parcela o la chacra para el campesino; es en cambio homogeneidad, continuidad, área inexpresiva equiparable a cualquier otra que sea susceptible de explotación y posibilidad de adineramiento. No es el lugar domesticado y morada del Agri-Cultor, sino paisaje chato despojado de afecto y significación poética. Es finca cuantificada, mercancía, bien transable, propiedad delimitada en linderos y expresable en escrituras notariadas. No es ya el terruño desde donde se construye "un mundo" sino espacio desencantado, insensible, reserva de existencias y recursos, objeto dirigible y manipulable, bodega de acervos, banal tierra innombrable.

Pero la "revolución verde” también incluye en su catálogo de ruinas la inmisericorde infamia contra los animales, por la cual, esos seres que habían sido traídos a casa para el habitar, han sido recluidos en campos de concentración y degradados a prisioneros perennes. Se han convertido en máquinas de producción a los cuales se les ha manipulado su genética, cortado sus picos, extraído de sus pastos, sustraído del descanso y privado del derecho a la noche. No son más animales concretos que crean afectos en los cuerpos de sus cultores, sino objetos anónimos e inertes coaptados por un fascismo encubierto. 
Ya hombres y mujeres no se reconocen como pastores, ni se asume la responsabilidad del cuidado y cultivo de la tierra sagrada, sino que toda acción está a la orden del lucro como fin último de una mal llamada existencia. Rememorando al Fausto de Goethe, ya no se indaga por aquello que mantiene unido al universo en lo más profundo, sino que el capitalismo moderno se pregunta por las acciones instrumentales más adecuadas para explotar mejor a un planeta puesto por él mismo a su servicio. El interés contemporáneo se orienta a interrogar por los mecanismos científicotécnicos y los modelos adecuados para que la naturaleza esté a total disposición del crecimiento económico y el desarrollo, y por las estrategias necesarias para hacer sostenible a un capitalismo cada vez más cansado y enfermo. Y así, entre el embrujo de esas divagaciones utilitaristas, su ser está quedando arrojado a un mundo estéril y devastado, huérfano de toda significación, y despojado del afecto original y sagrado que antaño lo unía a la tierra.

Sin embargo, el cientificismo hacedor de fórmulas y de manipulación genética cree haber conocido el mundo. Pero entre más lo razona y lo hace medible, calculable y ordenable, la verdad esencial se aleja volviéndose inasequible y esquiva. Se van estrechando los medios de entender lo que hace posible que la vida sea vida, porque entre más intenta escudriñar en los confines génicos en favor de la acumulación económica, más incrementa el peligro de impedir las condiciones necesarias para continuar subsistiendo.

Así, al establecer monocultivos y al introducir semillas alteradas en su secreto más íntimo, rompe la integración entre cultivos y sistemas ecológicos, y erosiona genéticamente la diversidad de la vida reacomodada naturalmente por siglos en nichos localizados. Se sustituyen los ciclos de nutrientes de las cadenas tróficas por flujos lineales basados en la gran producción industrial urbana, lo que resulta en el empobrecimiento y destrucción de la fertilidad de los suelos, contaminación hídrica y atmosférica, deforestación, devastación de la biodiversidad, lo que en últimas significa la aniquilación de las interrelaciones de las que dependemos para continuar perviviendo.

Pero si los efectos los vemos además desde la perspectiva de una ontología de la Agri-Cultura, podría ser posible que durante las intrincadas manipulaciones, los ordenamientos geométricos de los espacios, la destrucción de plantas y animales inútiles para el capital, y en general, a través de todos los dispositivos de disciplinarización de la naturaleza, el ser de ese ser humano controlador y enajenador también se haya alterado. Si es cierto aquello de que somos una continua creación humana; que nos hacemos a través de la experiencia en un mundo vivido, y que las interacciones recurrentes entre los seres vivos y el medio generan perturbaciones recíprocas (Maturana y Varela, 2003), no sería de extrañar que la violencia contra las congruencias del mundo natural, estén generando afectaciones en las personas compatibles con ese racional competitivo que divorcia, fragmenta, desplaza, disciplina y devasta la otredad. 
Es decir: la In-Cultura de la "revolución verde” no solo representa un atentado contra la supervivencia de todas las formas de existencia, sino que a través de ese hacer, crónicamente se va gestando una transformación ontológica análoga a lo que se hace con la naturaleza de la que se es emergencia. Muy similar a como la Agri-Cultura hace seres humanos, existe el peligro de que los modelos lineales fordistas encajados forzadamente a la ciclicidad de la naturaleza estén creando también cierto tipo de personas. En otras palabras, si al igual como la experiencia cotidiana en la milpa produce formas de ser congruentes con el ser de la milpa, los espacios modificados bajo el racional del monocultivo terminan habitando los cuerpos de quienes hacen monocultivos. Se van convirtiendo en lugares encarnados que forman seres competitivos, destructivos, solitarios, desconfiados. Seres extraviados de la tierra y sometidos al engranaje de un sistema industrial que devasta las complejas tramas de la vida.

\section{Agroecología y comprensión de la lengua común}

Por fortuna, pese a la violenta incursión del exterminio de la InCultura innombrable, la Agri-Cultura se mantiene, aún perdura, persiste. El dogma del desarrollo la ha minado, pero aún muchas comunidades rurales practican el "arte de cultivar y habitar la tierra". Mediante técnicas adecuadas se interaccionan con el medio, y en co-surgimiento van conociendo y haciéndose de acuerdo con el ser de la naturaleza.

Por tal motivo los estudios agroecológicos deben ser más que frías comparaciones de rendimientos entre sistemas. Mucho más, tienen que asumir la responsabilidad de ser matrices de transición civilizatoria (Torres, 2006) en permanente comprensión de la condición poética, cúltica y simbólica que emerge durante la labor de la Agri-Cultura. Les corresponde ser interpretación de sociedades rurales sumergidas en la naturaleza mediante actos localizados (Escobar, 2000), así como develamiento de las inmanentes asociaciones entre el ser, el hacer y el conocer enraizadas a lugares específicos (Maturana y Varela, 2003). Pero además tendrían que convertirse en agoreros del peligro que corre la especie humana de ser emplazada a desaparecer, y alerta del riesgo de acaecer completamente transfigurada bajo la lógica del monocultivo.

La agroecología a diferencia de las ciencias que estudian el paradigma industrial del capitalismo, es disciplina que da prelación a la interrelación, que presta atención a la totalidad, que da cuenta de las articulaciones, entrelazamientos e interdependencias de lo "visible". Y por visible hay que entender que si bien "la naturaleza gusta de ocultarse" como dice Heráclito, también es verdad que "no hay nada más visible que lo oculto", según profesa la sabiduría china. "De tanto ser visible, manifiesto, lo visible deja de serlo, uno ya no le presta atención” asegura François Jullien (2001: 65). Porque lo oculto no es el misterio escondido que toca escrutar en los laberintos bioquímicos de las células. Es por el contrario todo aquello que no llegamos a ver porque, precisamente, nunca ha dejado de exponerse. Lo 
más difícil de ver son las cosas que nunca se esconden y que permanecen siempre a la vista (Jullien, 2001). No es necesario buscar lo oculto en los ácidos nucleicos, ni en las partículas subatómicas, ni en las galaxias lejanas, aunque todo ello produzca conocimiento. En realidad todo lo esencial se encuentra en lo evidente, en las claras relaciones que se le escapan a los más sofisticados métodos científicos.

Como el saber del Agri-Cultor, la agroecología debe ser la herramienta del saber de lo evidente, para hacer visible lo invisible, volver audible lo inaudible, hacer que se advierta lo manifiesto. Sin embargo, debe mantener la cautela y serenidad para no caer en la arrogancia de creer que con su ciencia se ha llegado por fin a estar en "posesión del código secreto según el cual la naturaleza misma se expresa” (Pardo, 1991:114-115). Hay cosas que no pueden entenderse. Se nos muestran pero cuando vamos a su encuentro a través de la razón se nos esconden. Por eso la ciencia debe aprender a la renuncia, a la quietud, a "no hacer". Hay acciones factibles para el mundo técnico, cuestiones que podrían saberse y hacerse, pero que en realidad nos alejan del conocimiento de lo esencial, del asombro, del misterio al que el campesino nos enseña que hay rendirle culto.

A la agroecología le corresponde la tarea de develar la ontología misma de la Agri-Cultura, desocultar su significado en torno al habitar y el permanecer. Debe pensar ambientalmente dentro de un caos -ya no orden-que vuelva a reconocer la lengua común amordazada por las teleologías del progreso y el desarrollo (Noguera, 2012). Estamos viviendo en una época de profundos dilemas existenciales, de estructural crisis civilizatoria, y la única forma de salir -si es que eso aún es posible-, es retornar a los conocimientos, haceres y formas de ser congruentes con los principios de los ecosistemas, es decir, que seamos capaces de habitar escuchando el lenguaje de la naturaleza. 


\section{Notas}

* Este artículo hace parte del proyecto de investigación: “Crítica de la razón sostenible: una arqueología del saber y una genealogía del poder en tiempos de crisis ambiental” realizado por el Grupo de Trabajo Académico en Pensamiento Ambiental de la Universidad Nacional de Colombia sede Manizales. Agradezco especialmente a la Dra. Ana Patricia Noguera por su asesoría en la estancia doctoral durante la cual escribí el presente ensayo.

${ }^{1}$ Neologismo que significa “creación de sí mismo”.

${ }^{2}$ Kraemer, Gabriela. Comunicación electrónica. 07-07-2011. 


\section{Bibliografía}

Altieri, M. (1999), Agroecología. Bases científicas para una agricultura sustentable, Editorial Nordan-Comunidad, Montevideo.

Ángel, A. (1995), La fragilidad ambiental de la cultura, Editorial Universidad Nacional de Colombia-Instituto de Estudios Ambientales, IDEA, Bogotá.

Ídem (1996), El reto de la vida. Ecosistema y cultura, Ecofondo, Bogotá.

Bartra, A. (2010), “De milpas, mujeres y otros mitotes”, en La jornada del campo, 17 de abril, Número 31. México D.F.

Capra, F. (1998), La trama de la vida, Editorial Anagrama, Barcelona.

Collier, J. (1995), El derecho zinacanteco: procesos de disputa en un pueblo indígena de Chiapas, CIESAS, México, D.F.

Eliade, M. (1981), Lo sagrado y lo profano, Guadarrama, Barcelona.

Escobar, A. (2000), “El lugar de la naturaleza y la naturaleza del lugar ¿globalización o postdesarrollo?”, en La colonialidad del saber: eurocentrismo y ciencias sociales. Perspectivas latinoamericanas. Lander, E. Comp, CLACSO, Buenos Aires.

Estermann, J. (1998), Filosofía andina. Estudio intercultural de la sabiduría autóctona andina, Ediciones Abda-Yala, Quito.

Foucault, M. (2006), Historia de la sexualidad III. El Cuidado de sí. Siglo XXI Editores, Madrid.

Geertz, C. (1991), La interpretación de las culturas, Editorial Gedisa, Barcelona.

Heidegger, M. (1983), “Como cuando en día de fiesta...”, en Interpretaciones sobre la poesía de Hölderlin. Ariel, Barcelona.

Ídem. (1994a), “Construir, habitar, pensar”, en Conferencias y Artículos. Ediciones del Serbal, Barcelona.

Ídem. (1994b), "Poéticamente habita el hombre”, en: Conferencias y Artículos. Ediciones del Serbal, Barcelona.

Ídem. (1994c), Serenidad. Ediciones del Serbal, Barcelona.

Janke, W (1988), Postontología, Pontificia Universidad Javeriana - Organización de los Estados Iberoamericanos para la Educación la Ciencia y la Cultura, Bogotá. 
Jullien, F. (2001), Un sabio no tiene ideas. Ediciones Siruela, Madrid.

Lenkersdorf, C. (2005), Filosofar en clave tojolobal, Miguel Ángel Porrúa, México D.F.

Lerner, G. (1990), La creación del patriarcado. Editorial Crítica, Barcelona.

Maturana, H. y Varela, F. (2003), El árbol del conocimiento. Las bases biológicas del conocimiento humano. Lumen, Buenos Aires.

Noguera, A. (2004). El reencantamiento del mundo. PNUMA-Universidad Nacional de Colombia, México D.F.

Noguera, A. (2009). Cuerpo-Tierra. El enigma, el habitar, la vida...Emergencias de un pensamiento ambiental en clave del reencantamiento del mundo. Inédito, Manizales.

Noguera, A. (2012), (Comp.), Afecto-tierra. Disolución, imaginación y conspiración... Potencias del pensamiento ambiental, Inédito, Manizales

Pardo, J. (1991), Sobre los espacios Pintar, escribir, pensar. Ediciones del Serbal, Barcelona.

Saint-Exupèry, A. (1953), El principito. Publicaciones y Ediciones Salamandra, Barcelona.

Shiva, V. (2007), Los monocultivos de la mente. Editorial Fineo, Monterrey.

Torres, G. (2006), Poscivilización: Guerra y ruralidad. Plaza y Valdés, México D.F.

Varela, F. (2000), El fenómeno de la vida. Dolmen Ediciones, Santiago de Chile.

Recibido: 08.01.2013

Aceptado: 07.03.2013 